\title{
March 2013 editorial: Operational Statistics for the APESM Journal (Jan 2012-Feb 2013)
}

\author{
Martin Caon
}

Published online: 16 March 2013

(C) Australasian College of Physical Scientists and Engineers in Medicine 2013

APESM is quite a different entity in 2013 than it was when I last wrote about the state of the journal in 2009 [1]. Among other things, from 2010, the journal has been published by Springer and since 2009 the number of published articles has doubled and the number of submissions has almost tripled. Springer's online manuscript submission and tracking system makes it easy to extract summary data, some of which is presented below.

In 2008, APESM volume 31 published 39 scientific articles. Fifty-three manuscripts were submitted in that calendar year of which 42 were eventually published. Fifty-two articles were published in volume 35. In calendar year 2012, 134 manuscripts were submitted of which 25 (so far) have been published with 85 (so far) having been rejected. The current high rate of rejection is a reflection both of the rigour of the peer review process and of the diversity of submitted manuscripts.

The increase in submissions may be attributed to the increased visibility of APESM since being published by Springer, and in turn this is largely due to the journal's website and the growth in the use of the internet. Furthermore, accepted manuscripts are published on the website as soon as they are ready (and they may be cited with the digital object identifier-DOI). Hence, rather than waiting for the paper copy of the issue to be assembled, such articles are immediately visible to internet searches.

\section{Submissions}

The number of manuscripts submitted annually to APESM currently stands at about 135 . In the 25 months between

M. Caon $(\bowtie)$

School of Nursing \& Midwifery, Flinders University,

GPO Box 2100, Adelaide, SA 5001, Australia

e-mail: martin.caon@flinders.edu.au
January 2011 and the January 2013, manuscript submissions came from 28 countries: Algeria, Australia, China, Czech Republic, Egypt, Estonia, Germany, Greece, India, Iran, Italy, Jamaica, Japan, Korea, Malaysia, Mexico, New Zealand, Pakistan, Poland, Saudi Arabia, Serbia and Montenegro, South Africa, Spain, Sri Lanka, Sweden, Taiwan, Thailand, Turkey and Viet Nam.

It is clear that while APESM receives manuscripts from all over the world (with the significant exceptions of North and South America and the United Kingdom), the majority are from Australasia, Asia and the Middle East.

The countries from which manuscripts arrived most frequently in the time between January 2011 and February 2013 and the present were (in descending order) Iran, Australia, China, India, Malaysia, Japan and New Zealand.

The number of submitted manuscripts seems to increase year by year and this trend is seen in many journals. Between 2001 and 2004, submissions to APESM increased by $157 \%$ (albeit from a low base), and between 2004 and 2011, increased by $124 \%$. The corresponding numbers for Physics in Medicine and Biology are 67 and $94 \%$ (and for 2001-2004 for Physica Medica the increase was $20 \%$ ) [2]. Submissions to Medical Physics between 2006 and 2011 increased by $45 \%$ (and for the same period submissions to APESM rose by $210 \%$ ).

\section{Acceptance rate}

When scientific work is submitted for peer review, some will be found to be below the level required for publication, even after revision. Rejection may be for reasons of flawed work; or (if the work is sound) for lacking scientific novelty; withdrawal by authors (often after a poor review); unsuitability of the content for the journal; or plagiarism 
(and increasingly this is self-plagiarism). The rates of acceptance are not uniform-they vary with country of origin. Manuscripts from "western" (and English-speaking) countries have significantly higher acceptance rates than from other countries. Nevertheless, it is of interest to know the overall proportion of submissions that get published after peer-review.

Our acceptance rate is showing a downward trend that counter-matches the upward trend in the number of manuscripts submitted from non-western and non-English speaking countries. In calendar year 2011, APESM received 122 submissions, 48 of these were published (40\% acceptance, down from $79 \%$ acceptance in 2008). The acceptance rate for manuscripts submitted in 2012 will be less than $38 \%$. This is at the lower end of manuscript acceptance rates for comparable journals.

For comparison, in 2011 the publishing behemoths that are Physics in Medicine and Biology and Medical Physics (who are more than an order of magnitude greater in size than APESM) received (respectively) 1,400 submissions, and published $\sim 540$ articles ( $\sim 38 \%$ acceptance); and 1,104 submissions, publishing 681 articles $(\sim 60 \%$ acceptance). For 2012, the PMB reviewers' website states: "The journal currently accepts $45 \%$ of submitted papers."

For further comparison, IEEE Transactions on Biomedical Engineering published 485 articles in 2012 from more than 2,000 submissions (acceptance $24 \%$ ); the Polish Journal of Medical Physics accepts about $85 \%$ of submissions; Physica Medica (in 2004/5) accepted 50-60\% of submitted manuscripts. The open access journal: the Journal of Applied Clinical Medical Physics received (on average for the years 2009-2011) 200 manuscripts per year and accepted almost $60 \%$.

An eclectic list of journals with their acceptance rates (at various points in time!)

Behavioural Neuroscience acceptance rate declined from $54 \%$ (2004) to $40 \%$ (2011) [6];

Biomedical Imaging and Intervention Journal, about $70 \%$ acceptance between July 2005 and December 2007;

Clinical and Experimental Ophthalmology, 2011 acceptance rate was $26 \%$ [7];

European Journal of Nuclear Medicine acceptance of $40 \%$ in 1995 ;

Journal of Medical Physics had $\sim 70 \%$ acceptance in 2006;

Journal of Pharmacology and Experimental Therapeutics (2011) Acceptance Rate: $39 \%$ [8]

\section{Plagiarism}

I have mentioned plagiarism as a reason for rejection. Unfortunately this is a continuing concern for editors of medical physics journals [3-5] as well as others. In 2012 so far $8 \%$ of manuscripts have been rejected (prior to being sent for review) for plagiarism. These instances have often been of the easily detected "copy-from-published-sourceson-the-web and paste-into-the manuscript" kind. Others have been attempts at duplicate (or almost so) publication.

For comparison, the medical journal Anaesthesia \& Analgesia has, on the grounds of plagiarism, rejected $\sim 10 \%$ of manuscripts over the previous 2 years (Steven Schafer personal communication). Baždarić et al. checked all manuscripts submitted to the Croatian Medical Journal in 2009 and 2010 using plagiarism detection software. Manual verification confirmed that $11 \%$ of manuscripts were plagiarized [9]. These numbers seem small compared to the $31 \%$ of papers submitted to the Journal of Zhejiang University-Science (designated as a key academic journal by the National Natural Science Foundation of China) which were detected to contain "unoriginal material" [10].

\section{Reviewers}

During the period in question, 1,311 invitations to review were sent and slightly more than $50 \%$ of invitations were accepted. Reviewers were recruited from 48 countries (see APESM 34(4), p649 and 35(4) p515 for the acknowledgement of reviewers), predominantly from countries where English is the spoken language (rather than from the countries from which most manuscripts originate). In descending order, the nine countries in which most reviewers were residents are: Australia, USA, the United Kingdom, Canada, Iran, India, Germany, New Zealand and the Netherlands. Of the countries (excluding Australia and New Zealand) from which came the highest number of submitted manuscripts, their ranking in order of the number of reviewers supplied, is: Iran 5th, India 6th, China 12th, Korea 12th and Malaysia 16th.

Surprisingly no manuscripts were submitted from four of the nine leading reviewer source countries (i.e. UK, Canada, USA and the Netherlands). It seems that authors from these countries publish in Physics in Medicine and Biology, Medical Physics and in the IEEE Transactions.

Martin Caon, Editor, APESM

\section{References}

1. Caon M (2009) State of the Journal, APESM Statistics 2005-2008, Australas Phys Eng Sci Med 32(1), xiii-xiv

2. Data for journals other than APESM were sourced from the internet

3. Caon M (2007) Plagiarism in scientific/medical physics publishing, Australas Phys Eng Sci Med 30(4), xi-xii 
4. Hendee W (2007) A concern about plagiarism, J Med Phys 2007; 32(4): 143-144

5. Orton CG (2009) Concerns of Editors and publishers: Plagiarism, rights of authors, Open access etc World Congress on Medical Physics and Biomedical Engineering 2009, IFMBE proceedings 25/XIII pp 5-7

6. http://www.apa.org/pubs/journals/statistics.aspx. Accessed 14 March 2013

7. http://www.ncbi.nlm.nih.gov/pubmed/20092595. Accessed 14 March 2013
8. http://www.aspetjournals.org/site/misc/Accept_Rates_Impact_ Factors.xhtml. Accessed 14 March 2013

9. Baždarić K, Bilić-Zulle L, Brumini G, Petrovečki M (2012) Prevalence of plagiarism in recent submissions to the Croatian Medical Journal. Sci Eng Ethics 18(2):223-239

10. Yuehong Z (2010) Nature 467, 153 http://www.nature.com/ nature/journal/v467/n7312/full/467153d.html. Accessed 14 March 2013 